\title{
Review
}

\section{MicroRNAs as regulators of death receptors signaling}

\author{
M Garofalo ${ }^{1}$, GL Condorelli ${ }^{2}$, CM Croce ${ }^{1}$ and G Condorelli, ${ }^{*, 3,4}$
}

\begin{abstract}
Death receptors, belonging to the TNF receptor superfamily, induce apoptosis through two different pathways, one involving the effector caspases directly (type I cells or mitochondria-independent death), the other one amplifying the death signal through the mitochondrial pathway (type II cells or mitochondria-dependent death). MicroRNAs (miRNAs) are a class of small noncoding RNAs that regulate the stability or translational efficiency of targeted messenger RNAs. MiRNAs are involved in many cellular processes that are altered in cancer, such as differentiation, proliferation and apoptosis. In this review we will discuss recent findings implicating miRNAs as regulators of death receptors and pro- and antiapoptotic genes involved in programmed cell death pathways.

Cell Death and Differentiation (2010) 17, 200-208; doi:10.1038/cdd.2009.105; published online 31 July 2009
\end{abstract}

\section{MicroRNAs and death receptors}

MicroRNAs (miRNAs or miRs) are a class of endogenous noncoding, highly conserved RNAs of around 22 nucleotides in length, that are encoded in plant and animal genomes. ${ }^{1}$

They negatively regulate mRNA expression by repressing translation or directly cleaving the targeted mRNA. ${ }^{2}$ In the past few years, our understanding of the role of miRNA has expanded from the initially identified functions in the development of round worms to it becoming a highly expressed and ubiquitous regulator implicated in a wide array of critical processes, including proliferation, cell death and differentiation, ${ }^{3}$ metabolism ${ }^{4}$ and, importantly, tumorigenesis. ${ }^{5}$ MiRNAs are thought to regulate about $30 \%$ of the protein-coding genes of the human genome, and individual miRNAs typically target several transcripts rather than just one specific gene. ${ }^{6}$

Death receptors are cell-surface receptors belonging to the tumor necrosis factor (TNF) superfamily that includes CD95 (FAS/APO-1), TNF-R1 and TRAIL receptors (Table 1). All death receptors carry a conserved cytoplasmic domain of about 89 aa called the death domain (DD). The DD is a structurally conserved protein-interaction domain (consisting of six antiparallel $\alpha$-helices) which is important in the initiation of apoptotic signals. ${ }^{7}$ On ligand binding, death receptors trimerize and recruit adaptor molecules to form the deathinducing signaling complex (DISC); this initiates a cascade of events leading to caspase activation and finally to cell death.

The influence of regulatory noncoding RNA on apoptotic cell-signaling has not been extensively explored, but increasing evidence is pointing microRNA as a controller of intrinsic developmental and proliferative cell programs and ligandinduced cell signaling.
MicroRNAs and TRAIL. TNF-related apoptosis-inducing ligand (TRAIL; also known as Apo2L and TNFSF10) is a type II transmembrane protein belonging to the TNF superfamily. TRAIL was initially identified and cloned based on sequence homology of its extracellular domain with CD95L (28\% identical) and TNF (23\% identical). ${ }^{8}$ Humans have five distinct TRAIL receptors ${ }^{9}$ that are encoded by separate genes. DR4 (TNFRSF10a, TRAILR1) and DR5 (TNFRSF10b, TRAILR2) have been shown to form both homomeric and heteromeric complexes ${ }^{10}$ (Table 1). The other three receptors appear to act as 'decoys'. Decoy receptor 1 (DcR1) ${ }^{11}$ and DcR2 have a truncated, nonfunctional cytoplasmic DD; in addition, DcR1 lacks a cytosolic region and is anchored to the plasma membrane through a glycophospholipid moiety. Therefore, both receptors are incapable of transmitting an apoptotic signal. The fifth TRAIL-binding receptor is osteoprotegerin (TNFRSF11b): this is a soluble protein that may also function as a decoy/inhibitor by sequestering TRAIL extracellularly.

TRAIL is being developed as a promising antitumor agent that induces apoptosis in several tumor-derived cell types but rarely in normal cells, through the activation of caspases. ${ }^{12}$ Unfortunately, many human cancers are resistant to TRAILinduced apoptosis; the mechanism of this resistance is not clear. To address the gene networks regulating TRAILinduced apoptosis by a large scale screening, Ovcharenko et al. transfected 17000 unique siRNAs and $\sim 200$ synthetic miRNAs in MDA-MB-453 breast cancer cells. Their results indicated that 36 genes, including previously identified components of the apoptotic pathway, and 34 miRNAs participate directly or indirectly in the regulation of apoptosis.

\footnotetext{
${ }^{1}$ Department of Molecular Virology, Immunology and Medical Genetics, Comprehensive Cancer Center, Ohio State University, Columbus, OH, USA; ${ }^{2}$ RCCS MultiMedica, Milan, Italy; ${ }^{3}$ Department of Cellular and Molecular Biology and Pathology, University of Naples Federico II, Naples, Italy and ${ }^{4}$ Istituto di Endocrinologia ed Oncologia Sperimentale, CNR, IEOS, Naples, Italy

${ }^{*}$ Corresponding author: G Condorelli, Department of Cellular and Molecular Biology and Pathology, University of Naples Federico II, via Pansini 5, 80131, Naples, Italy. Tel: + 39081 7464416; Fax: + 39081 7463308; E-mail: gecondor@unina.it

Keywords: death receptors; apoptosis; microRNA; tumorigenesis; antiapoptotic miRs; proapoptotic miRs

Abbreviations: TNF, tumor necrosis factor; miRNAs, microRNAs; DISC, death-inducing signaling complex; TRAIL, TNF-related apoptosis-inducing ligand; DD, death domain.

Received 07.4.09; revised 27.5.09; accepted 30.6.09; Edited by G Melino; published online 31.7.09
} 
Table 1 TNF superfamily. TNF receptors and ligands are indicated with their localization

\begin{tabular}{|c|c|c|c|}
\hline Receptors & Ligands & Death domain & Localization \\
\hline $\begin{array}{l}\text { DR4/TRAILR1/TNFRSF10A } \\
\text { DR5/Apo2/TRAILR2/KILLER/DR5/ } \\
\text { TNFRSF10B }\end{array}$ & $\begin{array}{l}\text { Apo2/TRAIL } \\
\text { Apo2/TRAIL }\end{array}$ & $\begin{array}{l}\text { Yes } \\
\text { Yes }\end{array}$ & $\begin{array}{l}\text { Spleen, peripheral blood, lymphocytes, prostate, testis, ovary, uterus } \\
\text { Spleen, peripheral blood, lymphocytes, prostate, testis, ovary, uterus }\end{array}$ \\
\hline TNFR1(p55.CD120a) & TNF- $\alpha$, TNF- $\beta$ & Yes & Fibroblast, epithelial cells \\
\hline Fas/CD95 & CD95L & Yes & T cells, B cells, monocytes, neutrophils \\
\hline DcR1/TRAILR3/TRID/TNFRSF10C & TRAIL & No & Heart, placenta, lung, liver, kidney, spleen, leukocytes \\
\hline DcR2/TRAIL4/TRUNDD/NFRSF10D & Apo2L & No & Normal human tissue, tumor cell lines \\
\hline OPG/OCIF/TR1/TNFRS11b & OPGL/RANKL & No & Bone, endothelial cells \\
\hline CD30/TNFRSF8 & CD30L & No & Hodgkin's lymphoma cells \\
\hline TNFR2/CD120b/TNFRS1B & TNF- $\alpha$, TNF- $\beta$ & No & Hematopoietic cells \\
\hline CD40/TNFSF4/OX40/OX40L & CD40L & No & B cells, thymic epithelium, dendritic cell, monocytes, $T$ cells \\
\hline Rank/TNFRSF11A/TRANCE-R & RANKL & No & Cell surface of precursor bone cells \\
\hline DR3/WSL1/TRAMP/APO3/LARD & Apo3L & Yes & Thymocytes, lymphocytes \\
\hline DR6 & Unknown & Yes & Dendritic and tumor cells \\
\hline
\end{tabular}

Among these, DR4, DR5, TNFR-1, Fas/CD95, DR3 and DR6 are death receptors, able to trigger programmed cell death after the binding with their respective ligands.

The siRNAs that were shown to affect TRAIL-induced apoptosis targeted multiple genes involved in the TRAIL pathway and genes never implicated before, for example, CDK4, PTGS1, ALG2, CLCN3, IRAK4 and MAP3K8. Among the more interesting genes found to modulate apoptosis was CDK4, a cyclin-dependent kinase capable of inducing $G_{1}$ arrest in response to the DNA damage sensor, $p 53 .^{13}$ To identify miRNAs that might regulate apoptosis through deathreceptor signal transduction, MDA-MB-453 cells, transfected with 187 individual synthetic miRNAs probing the TRAIL pathway, were screened for phenotypic defects. Thirty-four of these miRNAs led to a differential caspase-3-activation phenotype. These included mir-10a, mir-28, mir-196a and mir-337, which induced caspase-3 activity, and mir-96, mir-145, mir-150, mir-155 and mir-188, which blocked caspase- 3 activation. The finding that miRNAs affect TRAILinduced apoptotic pathways confirmed that microRNA is involved in regulating ligand-induced apoptosis. In gliomas, miR-21 was reported to be upregulated, and miR-21 knockdown was associated with increased apoptotic activity. ${ }^{14}$ Furthermore, Corsten et al. evaluated the combined effects of miR-21 antagonism and expression in neural precursor cells (NPC) of a secretable variant of the cytotoxic agent, tumor necrosis factor-related apoptosis inducing ligand (S-TRAIL). They demonstrated that pretreatment of glioma cells with LNA-anti-miR-21 and NPC-mediated S-TRAIL delivery to glioma led to synergistic antitumor effects both in vitro and in vivo. ${ }^{15}$

Mott et al. reported that miR-29b regulates $\mathrm{Mcl}-1$ expression in cholangiocarcinoma cell lines. ${ }^{16} \mathrm{Mcl}-1$ is a potent multidomain antiapoptotic protein that contains Bcl-2-homology domains $\mathrm{BH} 3$ and that heterodimerizes with Bcl-2 family members. Specifically, $\mathrm{Mcl}-1$ binds to the $\mathrm{BH}$-only proteins Bim, Bid, Bik, Noxa and Puma, ${ }^{17}$ as well as Bak. ${ }^{18}$ Binding to Bid and Bim protects against TRAIL-induced cell death. Enforced miR-29b expression reduced the level of $\mathrm{Mcl}-1$ protein and sensitized cancer cells to TRAIL cytotoxicity. ${ }^{16}$

We recently addressed the implication of miRNAs in TRAIL resistance in four non-small cell lung carcinoma (NSCLC) cell lines having different sensitivities to TRAIL.
We found that miR-221 and miR-222 were markedly upregulated in TRAIL-resistant (Calu-1) and semiresistant (A459, A549) cells compared to TRAIL-sensitive (H460) NSCLC cells. ${ }^{19}$

The receptor tyrosine kinase Kit and the cycline-dependent kinase inhibitor, $\mathrm{p} 27^{\mathrm{kip} 1}$ are both functional targets of miR-221 and miR-222. ${ }^{20,21}$ However, we demonstrated that silencing p2 $7^{\text {kip } 1}$ but not Kit, increased resistance to TRAIL. This result well supports the involvement of miR-221 and miR-222 in determining the TRAIL-resistant/sensitive phenotype in NSCLC cells mainly by interfering with p2 $7^{\mathrm{kip} 1}$ expression and TRAIL-induced caspase machinery, and reveals a novel function of $\mathrm{p} 27^{\mathrm{kip} 1}$

Although many other cancer cells are resistant to TRAIL-induced cell death by still unknown mechanism, the above-mentioned studies indicate a promising link between TRAIL resistance and miRNAs. Therefore, it can be hypothesized that the modulation of miRNAs might become a viable therapeutic strategy to sensitize cancer cells to TRAIL-induced apoptosis.

MicroRNAs and TNF. TNF is a major mediator of apoptosis as well as of inflammation and immunity, and it has been implicated in the pathogenesis of a wide spectrum of human diseases, including cancer ${ }^{22}$ and autoimmune diseases. ${ }^{23}$

TNF binds to two specific receptors, TNF-receptor type I (TNF-R1, CD120a) and TNF-receptor type II (TNF-R2, CD120b; Table 1). These receptors differ in structure and function. A DD is present only in TNFR1, and thus, TNFR2 activation does not directly lead to caspase activation. TNFR2 is believed to initiate primarily proinflammatory and prosurvival signaling. On the other hand, TNFR1 activation leads to recruitment of intracellular adaptor proteins that activate multiple signal transduction pathways ${ }^{24}$ and can have two different end results that are dependent on the cellular context. The default pathway is the induction of genes involved in inflammation and cell survival. Binding of TNF- $\alpha$ to TNFR1 induces a range of inflammatory mediators and growth factors through activation of the AP transcription factors and nuclear factor- $\kappa \mathrm{B}$ (NF- $\kappa \mathrm{B})$. Importantly, NF- $\kappa \mathrm{B}$ 
activation induces negative regulators of apoptosis such as $\mathrm{Bcl} 2$ and superoxide dismutase. If $\mathrm{NF}-\kappa \mathrm{B}$ activation is inadequate, apoptosis is mediated through caspase-8 and through sustained Jun amino-terminal kinase (JNK) activation and mitochondrial pathways.

In this respect, TNF- $\alpha$ is a bifunctional molecule and the response of a cell to this agent probably depends on interplay between pro- and antiapoptotic signaling events. Studies on the interplay of miRNA and TNF have been based mainly on the effects of TNF and other inflammatory cytokines on expression of miRNAs; few studies investigating the effects of miRNA on the regulation of the TNF pathway have been reported so far.

To examine the potential involvement of miRNAs in the innate immune response, Taganov et al. analyzed expression profiling of 200 miRNAs on exposure of the human acute monocytic leukemia cell line, THP-1, to a variety of microbial and proinflammatory components. ${ }^{25}$

Several miRNAs (miR-146a/b, miR-132 and miR-155) were found to be upregulated in response to lipopolysaccharide (LPS) as well as to other microbial components and proinflammatory mediators, such as TNF- $\alpha$ and interleukin (IL)-1. Besides the identification of endotoxin-mediated upregulated miRNAs, the analysis of the promoter region of the miR-146a gene revealed that NF- $\kappa$ B plays a critical role in induction of its transcription by LPS, TNF $\alpha$ and IL-1 $\beta$. In addition, they determined TRAF6 and IRAK 1 as potential molecular targets of miR-146. These findings suggest that $\mathrm{miR}-146 \mathrm{a} / \mathrm{b}$ may function as a novel negative regulator that contributes not only to the fine-tuning of the immune response but also to the modulation of the apoptotic pathway in response to TNF- $\alpha$ and other proinflammatory mediators.

The involvement of mRNAs also in the innate immunity response was reported by Tili et al. They found that miR-155 and miR-125b were respectively upregulated and downregulated in mouse Raw 264.7 macrophages in response to LPS. The effect was specific for myeloid cells because human breast cancer cells did not display the same regulation. MiR-155 targeted the mRNA of apoptosis-regulating proteins such as IKK- $\varepsilon$, FADD and Ripk1. ${ }^{26}$

The role of $\mathrm{TNF}-\alpha$ in the regulation of miR-155 was demonstrated further in another study reporting that interferon (IFN)- $\gamma$ induced miR-155 in macrophages after $6 \mathrm{~h}$ of stimulation. ${ }^{27}$ Using TNFR1 ${ }^{-1-}$ macrophages, they demonstrated that IFN- $\beta$ and IFN- $\gamma$ failed to upregulate miR-155 in the absence of TNFR1 signaling. Together, these findings identify TNF- $\alpha$ as an inducer of $\mathrm{miR}-155$ and indicate that IFNs requires TNF- $\alpha$ autocrine/paracrine signaling to upregulate miR-155 in macrophages.

A recent study analyzing 365 miRNAs reported that miR-9 becomes upregulated in both human polymorphonuclear neutrophils (PMN) and monocytes by the proinflammatory cytokines TNF- $\alpha$ and IL- $1 \beta$, but not by IFN- $\gamma$.

Anti-TNF- $\alpha$ antibodies completely blocked TNF- $\alpha$-induced miR-9 upregulation. These data candidate miR- 9 as a novel miRNA involved in the responses of human phagocytes to selected stimuli of bacterial origin or proinflammatory cytokines. $^{28}$ In conclusion, although the relation between TNF- $\alpha$-induced apoptosis and microRNAs has not been fully elucidated yet, there is evidence of a correlation between
miRNAs and TNF- $\alpha$ in immunity. It is possible to hypothesize that as miRNAs regulate the TNF- $\alpha$ pathway in the immune response and vice versa, they may be also involved in TNF- $\alpha-$ induced cell death. Further studies are certainly needed to highlight the role of miRNAs in the TNF- $\alpha$-receptor-induced apoptosis pathway.

MicroRNAs and CD95. The initial events in CD95-mediated signaling after CD95 stimulation differ between type I and type II cells. In type I cells, caspase-8 is recruited to the DISC, resulting in the release of active caspase- 8 in quantities sufficient to directly activate caspase-3. ${ }^{29}$ However, despite similar expression levels of surface CD95 and signaling molecules, formation of the DISC is so inefficient in type II cells that only very small quantities of caspase 8 are generated. This amount of caspase- 8 is insufficient to process caspase-3, but sufficient to cleave the BH3-only protein, Bid, resulting in the apoptogenic activation of mitochondria. Therefore, the execution of apoptosis can be inhibited by overexpression of $\mathrm{Bcl}-2$ or $\mathrm{Bcl}-\mathrm{xL}$ only in type II cells. ${ }^{30}$ Division of type I and type II cells also matches the $\mathrm{NCl} 60$ panel of human tumor cell lines, classified into two superclusters (SC), SC-1 and SC-2, that present different grades of tumorigenicity.

Recently, Shell et al. determined whether miRNAs could regulate the difference between type I and type II cells by analyzing 10 type I and 10 type II cell lines by miRNA array. Four members of the let-7 family of miRNAs (let-7f, let-7d, miR-98 and let-7g) were expressed significantly higher in type II/SC2 cells, and among these, let-7d expression discriminated between the two groups more effectively than any of the tested miRNAs.

They also identify high mobility group A2 (HMGA2) as a let-7 target. The loss of let-7 induced the expression of HMGA2 and identified a mesenchymal cancer subtype in vitro and in vivo. ${ }^{31}$

As tumor cells with a mesenchymal gene profile represent more advanced stages of cancer, let-7 downregulation could be seen as a part of the process of tumor progression.

Taken together these results highlight that deregulation of microRNAs in type I versus type II cells could induce alterations in apoptotic pathways, increasing the oncogenic potential of cancer cells. Moreover, regulation in cancer cells of CD95 expression by an indirect action of miR-21 (see below) has been as well described ${ }^{32}$ and unmasks an alternative mechanism of evading CD95-mediated apoptosis in cancer cells.

\section{MicroRNAs and Apoptosis}

It is known that microRNAs could be classified as onco- and tumor-suppressor miRs, depending on whether the target is an onco- or a tumor-suppressor gene.

We discussed before how microRNAs are deregulated by death receptors activation; these data clearly involve them in the cell's response to signals of death or survival.

Below, we will highlight recent findings about selected microRNAs regulating pro- and antiapoptotic genes involved in the extrinsic and intrinsic pathways (Table 2 and Table 3). 
Table 2 List of antiapoptotic miRNAs with their respective targets and the conserved sites in different species

\begin{tabular}{|c|c|c|c|c|c|c|}
\hline miR & Gene Target & \multicolumn{3}{|c|}{ Conserved site } & Deregulation in cancer & Ref \\
\hline $\begin{array}{l}\text { miR-21 } \\
\text { 17q23.1 }\end{array}$ & PDCD4 & & 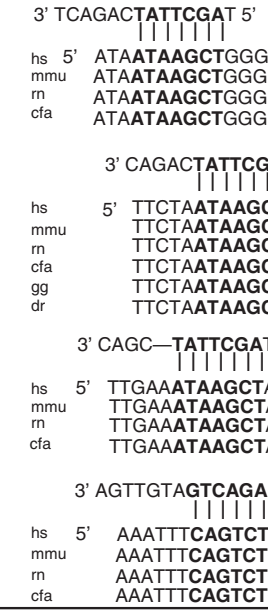 & 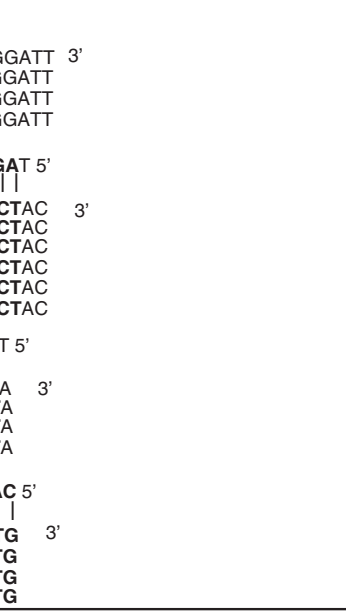 & $\begin{array}{l}\text { Overexpressed in } \\
\text { breast, lung, } \\
\text { prostate, colon, gastric, } \\
\text { esophageal, } \\
\text { glioblastoma, } \\
\text { cervical, head and } \\
\text { neck cancer. }\end{array}$ & $\begin{array}{l}35 \\
36 \\
\end{array}$ \\
\hline $\begin{array}{l}\text { miR-221\&222 } \\
\text { Xp11.3 }\end{array}$ & KIT & $\begin{array}{l}\text { miR-221 } \\
\text { miR-222 } \\
\text { miR-221 } \\
\text { miR-222 } \\
\text { miR-221 } \\
\text { miR-222 } \\
\text { miR-221 } \\
\text { miR-222 }\end{array}$ & 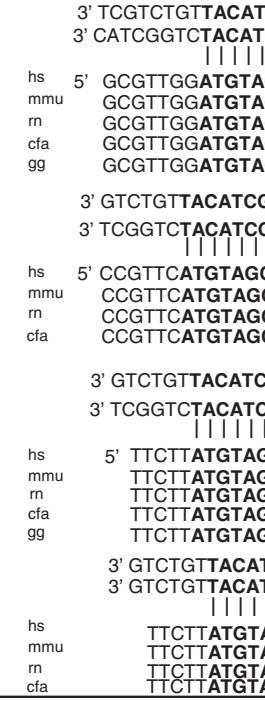 & 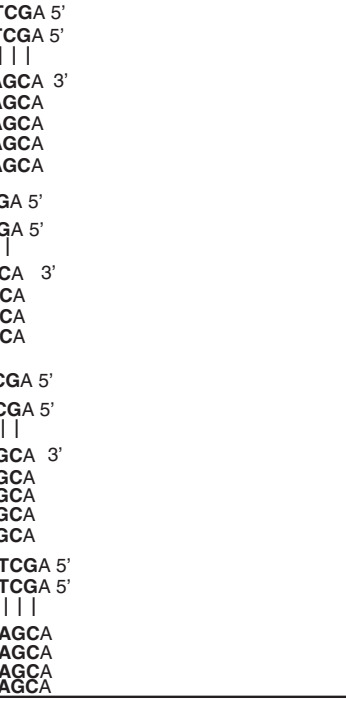 & $\begin{array}{l}\text { Upregulated in thyroid papillary } \\
\text { carcinoma, hepatocarcinoma, } \\
\text { CLL, glioblastoma, melanoma, } \\
\text { prostate and breast cancer. }\end{array}$ & $\begin{array}{l}21 \\
37\end{array}$ \\
\hline \multirow{3}{*}{$\begin{array}{l}\text { miR-106b- } \\
\text { 93-25 } \\
\text { cluster } \\
7 q 22.1 \\
\text { miR-17- } \\
\text { 92cluster } \\
13 q 31.3\end{array}$} & p21/CIP1 & 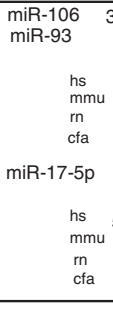 & $\begin{array}{c}\text { GACAGTCGTGAAAT 5' } \\
\text { 3' CTTGTCGTGAAAC 5' } \\
\text { 5' AAAGCACTTTT 3' } \\
\text { AAAAGCACTTTT } \\
\text { AAAAGCACTTTT } \\
\text { AAAAGCACTTTT } \\
\text { 3' GACATTCGTGAAAC 5' } \\
\text { | | | | | | | } \\
\text { 5' CAGATGGCACTTTG 3' } \\
\text { CAGATGGCACTTTG } \\
\text { CAGATGGCACTTTG } \\
\text { CAGATGGCACTTTG } \\
\end{array}$ & 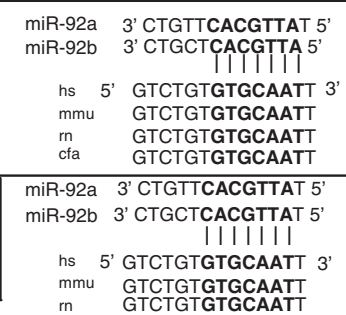 & \multirow[t]{3}{*}{$\begin{array}{l}\text { Overexpressed in } \\
\text { neuroblastoma, gastric, } \\
\text { colon, prostate cancer, } \\
\text { multiple myeloma. }\end{array}$} & \multirow[t]{3}{*}{39,40} \\
\hline & BIM & $\begin{array}{l}\text { miR-106 } \\
\text { miR-93 } \\
\\
\text { hs } \\
\text { mmu } \\
\text { rn } \\
\text { cfa } \\
\end{array}$ & $\begin{array}{l}\text { 3' GACAGTCGTGAAAT 5', } \\
\text { 3' GCTTGTCGTGAAAC 3' } \\
\text { 5' GACTAGAGCACTTTA } \\
\text { GACTAGAGCACTTTA } \\
\text { GACTAGAGCACTTTA } \\
\text { GACTAGAGCACTTTA } \\
\end{array}$ & $\begin{array}{cc}\text { cfa } & \text { GTCTGTGTGCAATT } \\
\text { miR-17-5p } & \text { 3' ACATTCGTGAAAC 5' } \\
\text { hs } & \text { 5' CTAGAGCACTTTA 3' } \\
\text { mmu } & \text { CTAGAGCACTTAA } \\
\text { rn } & \text { CTAGAGCACTTTA } \\
\text { cfa } & \text { CTAGAGCACTTTA } \\
\end{array}$ & & \\
\hline & E2F1 & $\begin{array}{l}\text { miR-17-5p } \\
\begin{array}{r}\mathrm{hs} \\
\mathrm{mmu} \\
\mathrm{rn} \\
\mathrm{cfa}\end{array} \\
\end{array}$ & $\begin{array}{l}\text { 3'GACATTCGTGAAAC 5' } \\
\text { 5' CAATCTGCACTTTG 3' } \\
\text { CAATCTGCACTTTG } \\
\text { CAATCTGCACTTTG } \\
\text { CAATCTGCACTTTG } \\
\end{array}$ & $\begin{array}{cl}\text { miR-20a } & \text { TATTCGTGAAAT } \\
& \\
\text { hs } & \text { 5ACTGCACTTTC } \\
\text { mmu } & \text { AACTGCACTTTC } \\
\mathrm{m} & \text { AACTGCACTTTC } \\
\text { cfa } & \text { AACTGCACTTTC } \\
\end{array}$ & & \\
\hline $\begin{array}{l}\mathbf{m i R}-155 \\
21 \mathrm{q} 21.3\end{array}$ & TP53INP1 & & $\begin{array}{l}\text { 3'GTGCTAATCGTAATT 5' } \\
\text { 5' AACATTAGCATTAA 3' } \\
\text { AACATTAGCATTAA } \\
\text { AACATTAGCATTAA } \\
\text { AACATTAGCATTAA }\end{array}$ & & $\begin{array}{l}\text { Upregulated in pediatric } \\
\text { Burkitt's lymphoma, Hodgkin's } \\
\text { lymphoma, breast, lung, colon, } \\
\text { and pancreatic cancer. }\end{array}$ & 42 \\
\hline
\end{tabular}

Hs, human; mmu, mus musculus; rno, rattus norvegicus; gg, gallus gallus; dr, drosophila; CLL, chronic lymphocytic leukemia; DLBCL, diffuse large B-cell lymphoma. 
Table 3 List of proapoptotic miRs with their respective targets and the conserved sites in different species

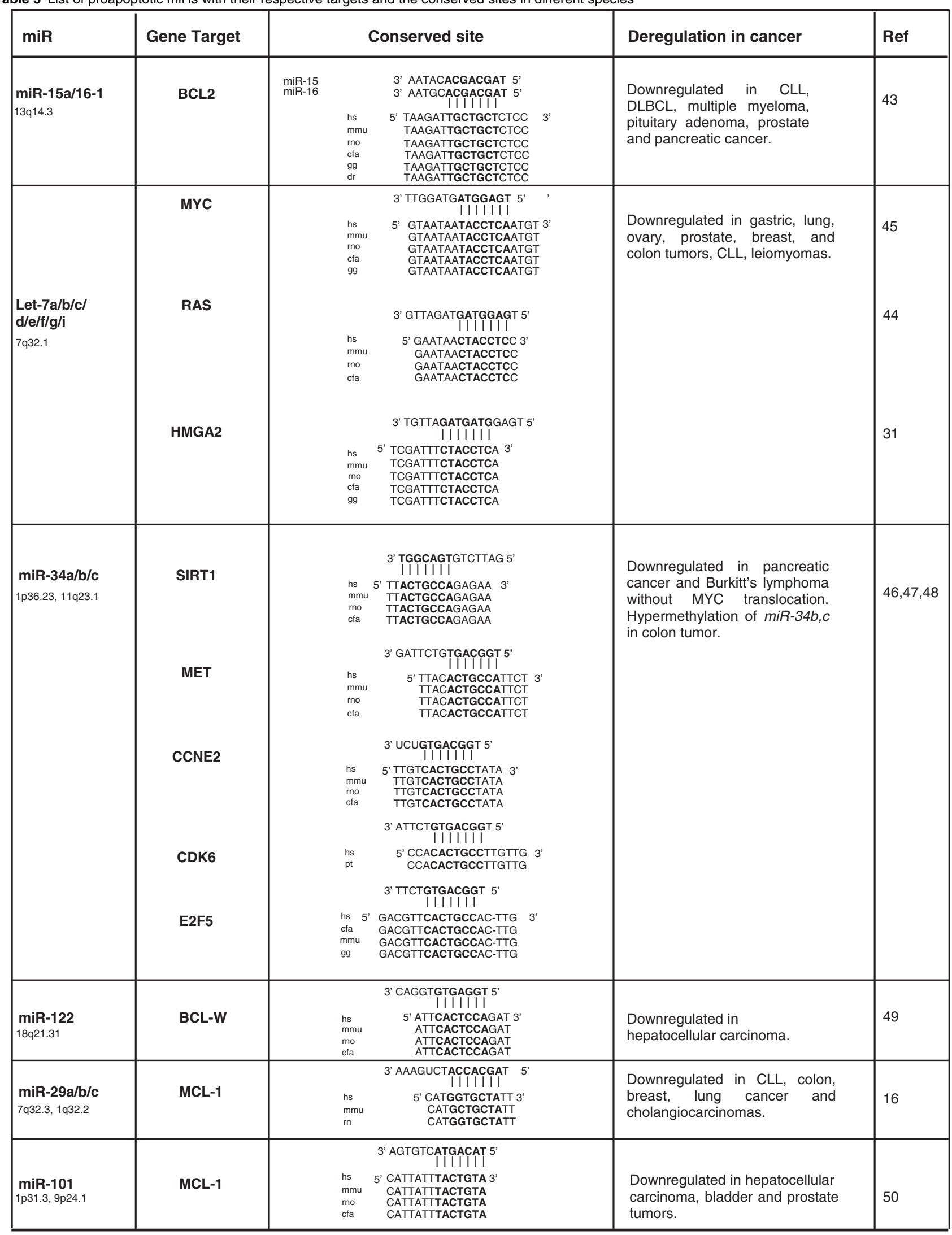

Hs, human; mmu, mus musculus; rno, rattus norvegicus; gg, gallus gallus; dr, drosophila; pt, Pan troglodytes (chimpanzee). 
Antiapoptotic microRNAs. A set of miRNAs have been shown to be upregulated in the majority of cancers profiled to date. The best characterized are miR-21, miR-222, miR-221, miR-17-92, miR-106 and miR-155 (Table 2). Chen et al., demonstrated that miR-21 overexpression inhibits PDCD4dependent apoptosis. ${ }^{33}$ PDCD4 is a tumor suppressor that inhibits tumor promoter-induced neoplastic transformation and the activation of AP-1-dependent transcription required for transformation. More recently, Papagiannakopoulos et al. reported for the first time that two important miR-21 targets are HNRPK, which codifies for an RNA-binding protein involved in cell-cycle progression, and TAp63, an important epithelial developmental gene that has significant homology to $553 .^{32}$ TAp63 directly transactivates the CD95 gene via the p53 binding site in the first intron of $C D 95$, resulting in upregulation of a functional CD95 death receptor. Stimulation and blocking experiments of the CD95, TNF-R and TRAIL-R death receptor systems revealed that TAp63 can trigger expression of each of these death receptors. Furthermore, TAp63 upregulates expression of proapoptotic Bcl-2 family members such as Bax and BCL2L11 and APAF1, demonstrating a link between TAp63 and the mitochondrial apoptosis pathway. Of clinical relevance is the fact that TAp63 inhibition leads to chemo resistance. ${ }^{34}$ Zhang et al. demonstrated that miR-21 is also significantly overexpressed in human gastric cancer tissues and cell lines. Forced expression of miR-21 significantly enhanced cell proliferation and invasion in AGS, a human gastric-cancer cell line; conversely, knockdown of miR-21 by inhibitors caused a significant reduction in cell proliferation and a significant increase in apoptosis by targeting $R E C K$, a known tumor suppressor, in gastric cancer. ${ }^{35}$

Further, expression-profiling studies using a miRNA microarray revealed that miR-21 is highly overexpressed in hepatocellular carcinoma (HCC) and its cell lines. ${ }^{36}$ Inhibition of miR-21 in cultured HCC cells decreased tumor-cell proliferation, migration and invasion by targeting phosphatase and tensin homolog (PTEN) tumor-suppressor gene. ${ }^{37}$ These results indicate that through its regulation of cellular process, miR-21 acts as an antiapoptotic factor in several cell lines and may serve as a target for effective therapies.

Recently, miR-221 and miR-222 have been shown to repress cyclin-dependent kinase (CDK) inhibitory proteins p27 ${ }^{\mathrm{Kip} 1}$ and p57 as well as the c-Kit receptor, leading to cell proliferation and survival and inhibition of cell differentiation. ${ }^{21,36,20}$

Zhao et al. reported that estrogen receptor- $\alpha(E R-\alpha)$ is a direct target of miR-221 and miR-222. Knockdown of miR-221 and miR-222 restores ER- $\alpha$ protein expression and sensitizes MDA-MB-468 cells to tamoxifen-induced apoptosis, whereas ectopic expression of miR-221 and miR-222 in MCF-7 and T47D cells reduces the ER- $\alpha$ protein level and renders the cells resistant to tamoxifen. ${ }^{38}$

Petrocca et al. performed a genome-wide analysis of miRNA expression at different stages of gastric carcinogenesis. Upregulation of the miR-106b-25 cluster impairs the TGF- $\beta$ tumor suppressor pathway, interfering with the expression of p21Waf1/Cip1 and Bim. These results suggest that the miR-106b-25 cluster plays a key role in gastric cancer by interfering with proteins involved in both cell cycle and apoptosis. $^{39}$
The miR-17-92 cluster, consisting of 7 members transcribed as a polycistronic unit driven by c-myc expression, is often overexpressed in cancers, including B-cell lymphoma.

Inomata et al. demonstrated that miR-17-92 downregulates the proapoptotic protein Bim and CDKN1A/p21 during B-cell lymphomagenesis. ${ }^{40}$

O'Donnell et al. showed that E2F1 is negatively regulated by two microRNAs of the miR-17-92 cluster, miR-17-5p and miR-20a. ${ }^{41}$

TP53INP1 is a proapoptotic stress-induced p53 target gene; its expression is dramatically reduced in pancreatic ductal adenocarcinoma (PDAC). Gironella et al. demonstrated that TP53INP1 expression is lost in early stages of pancreatic cancer evolution and that its restoration strongly reduces tumor development. Moreover, they showed that TP53INP1 is a direct target of miR-155, and is overexpressed in PDAC cells. ${ }^{42}$

Proapoptotic miRNAs. Among the proapoptotic miRNAs are $\mathrm{miR}-15$ and $\mathrm{miR}-16$, the let-7 family and the members of miR-34 family (Table 3).

MiR-15a and miR-16-1 are deleted or downregulated in the majority of chronic lymphocytic leukemias (CLL) and their expression is inversely correlated to $\mathrm{Bcl} 2$ expression in CLL. BCL2 repression by these miRNAs induces the activation of the intrinsic apoptotic pathway in hematopoietic cancer cells. ${ }^{43}$

Similarly, an inverse correlation exists between let-7 and RAS in lung tumors, and this provides a possible mechanism for let-7 in cancer. ${ }^{44}$

Moreover, Sampson et al. found that overexpression of let-7a decreased Myc mRNA and protein in lymphoma cells, suggesting that deregulation of this miRNA participates in the genesis and maintenance of the lymphoma phenotype in Burkitt lymphoma cells and other Myc-deregulated cancers. ${ }^{45}$

The miRNA-34 family comprises three members: miRNA$34 \mathrm{a}$, which is generated from a larger transcriptional unit on chromosome 1p36, and miR-34b and miR-34c, both of which are generated by processing of a bicistronic transcript from chromosome $11 \mathrm{q} 23$ (termed miR-34bc).

$\mathrm{He} L$ et al. identified miRNA components of tumor suppressor pathways, and compared miRNA expression profiles of wild-type and p53-deficient cells. MiR-34a-c is a direct transcriptional target of p53. Ectopic expression of miR34 induces cell-cycle arrest in both primary and tumor-derived cell lines, which is consistent with the observed ability of miR-34 to downregulate a set of genes promoting cell-cycle progression including cyclin E2 (CCNE2), cyclin-dependent kinase 4 (CDK4) and the hepatocyte growth factor receptor (MET), thus placing the miR-34 family among the proapoptotic miRNAs. ${ }^{46}$

The members of the miR-34 family have been discovered to be direct p53 targets. MiR-34 inhibition of SIRT1 in colon cancer cells leads to an increase in acetylated p53 and expression of p21 and PUMA, transcriptional targets of p53 that regulate the cell cycle and apoptosis, respectively. Therefore, a positive feedback loop between p53 and miR-34a ${ }^{47}$ exists that is involved in apoptosis resistance in human cancer. 


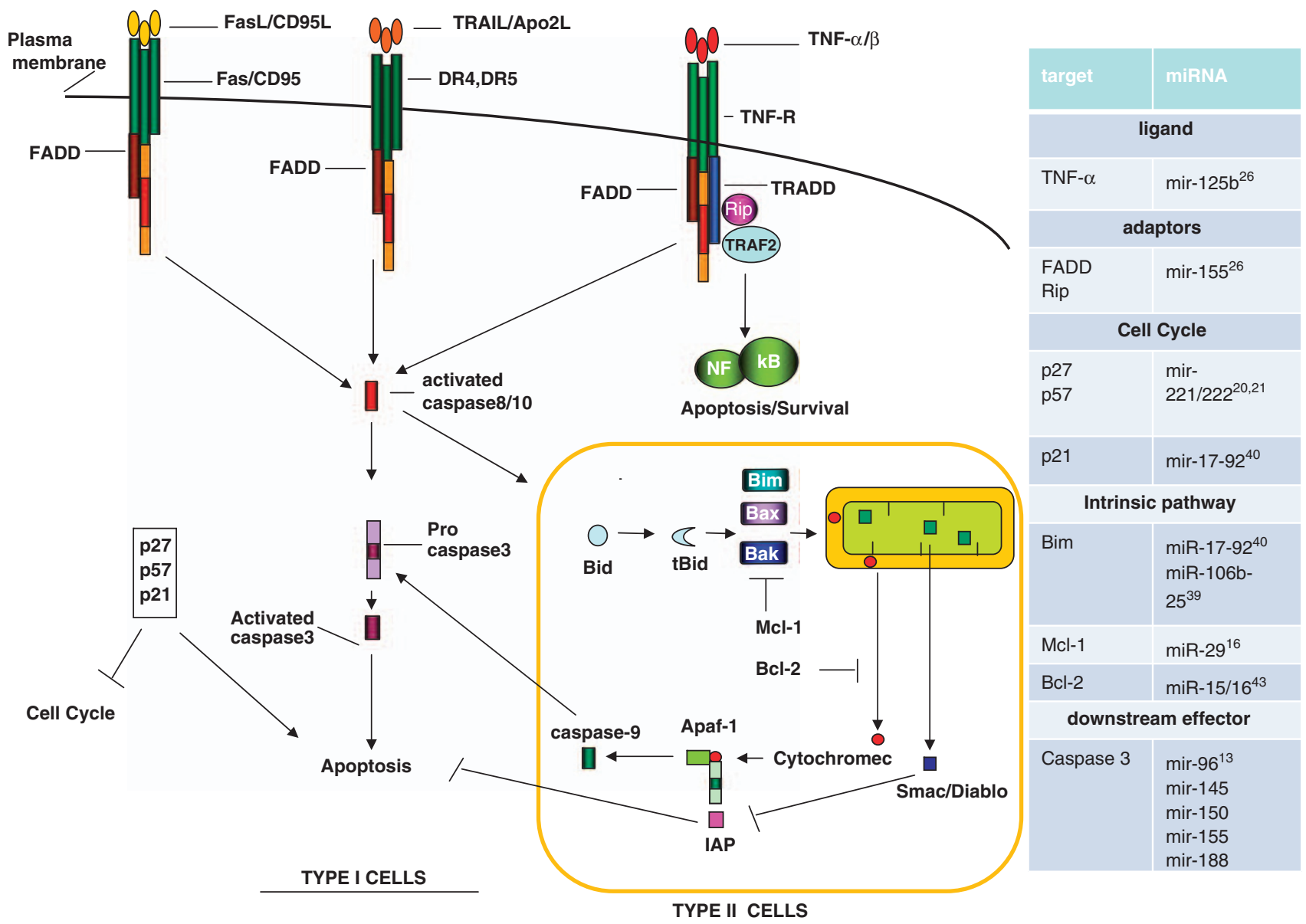

Figure 1 Death receptors and microRNAs. Known as the 'death receptor pathway', the extrinsic or caspase-8/10-dependent pathway is activated by ligands such as CD95/Fas, TRAIL, TNF- $\alpha$ and TNF- $\beta$. On the binding of cognate ligand, the activated death receptors trimerize and recruit Fas-associated death domain (FADD) and the initiator caspase-8. In this death-inducing signaling complex (DISC), caspase-8 is autoactivated by proteolysis and released into the cytosol; this leads to activation of caspase3 and subsequently to apoptosis (type I cells). Caspase-8 can also trigger the intrinsic pathway (in type II cells) through the cleavage of Bid. Cleaved Bid induces cytosolic release of cytochrome $\mathrm{c}$ and SMAC/Diablo. Cytochrome $\mathrm{c}$ binds the adaptor proteins, Apaf-1 and procaspase-9, consequently forming an apoptosome, which activates caspase-9 that activates caspase-3, resulting in apoptosis. The Bcl-2 family can inhibit apoptosis by preventing cytochrome c release into the cytosol. The inhibitor of apoptosis proteins (IAPs) block caspase activation further downstream. SMAC/Diablo displaces these IAPs, thus promoting apoptosis. The intrinsic pathway can also be triggered after DNA-damage by chemotherapy or radiotherapy. In the figure the microRNAs involved in the different pathways and the relative references are reported. MiR-125 downregulates TNF- $\alpha$. MiR-155 blocks the adaptor proteins FADD, Rip and caspase 3. MiR-221 and -222, by targeting p27 and p57, influence the cell cycle, as well as cell death. MiR-106b-25 and miR-17-92 target Bim and p21, influencing both cell cycle and apoptosis. MiR-96, miR-145, miR-150 and miR-188 act on the effector caspase-3

A further confirmation of the proapoptotic function of miR-34 family comes from the paper of Bommer et al. They observed, after miRNA34 induction in SW480 p53 mutant colon cancer cell line, a $\mathrm{G}_{1}$ arrest, which suggested that miRNA34, similar to $p 53$ itself, regulates cell-cycle progression. They confirmed that the expression of several cell-cycle regulators predicted to be regulated by miRNA34 as Cyclin E2, CDK6 and E2F5, was in fact reduced on ectopic expression of miRNA34a. ${ }^{48}$

MiR-122, a hepatospecific miRNA, is frequently downregulated in human $\mathrm{HCC}$. Lin et al. demonstrated that $\mathrm{BCl}-\mathrm{w}$, an antiapoptotic Bcl-2 family member, is a direct target of miR-122. Overexpression of miR-122 in the HCC cell lines, HepG2 and HepG3, led to reduction of cell viability and activation of caspase-3. ${ }^{49}$ Finally, Su et al. found that miR-101 sensitized hepatoma cell lines to both serum-starvation- and chemotherapeutic-drug-induced apoptosis by repressing MCL-1, indicating that miR-101 may exert its proapoptotic function via targeting $\mathrm{Mcl}-1 .{ }^{50}$ As described above, $\mathrm{Mcl}-1$ is also a target of miR-29b, and is upregulated in cholangiocarcinoma cell lines that overexpress miR-29b. ${ }^{16}$

\section{Conclusions}

Mounting evidence indicates that miRNA plays a fundamental role in tumorigenesis, controlling cell proliferation and apoptosis.

Recent findings suggest, in fact, that different miRNAs are upregulated in response to various proinflammatory mediators as TNF- $\alpha$ and IL-1; conversely, the binding of cytokines to death receptors seems to trigger an alteration in miRNA expression and, accordingly, in the expression of gene targets involved in the apoptotic or survival pathways. As expected, several of miRNAs that regulate the biological response to death receptors target key molecules of apoptosis. 
A significant observation is that more than one-quarter of all known human miRNAs are reported to be deregulated in at least one cancer type. .,41 $^{\text {Th }}$

The expression of a subset of miRNAs (e.g., miR-21, miR$221 / 222$, the miR-17-92 cluster) is found to be consistently upregulated, whereas another subset of miRNAs (miR-15, -16 , let-7) is consistently downregulated across different cancer types, suggesting that they are involved in regulating common cellular processes that may lead to tumorigenesis when dysregulated. Some miRNAs, such as miR-29b miR-1516, miR-196, miR-337 and miR-145 have been shown to influence only the apoptotic pathway, whereas others including miR-106b-25 and miR-17-92 may play roles in both the apoptotic and cell-proliferation pathways (Figure 1).

It is also thought that perturbation of miRNA expression may underlie resistance to chemotherapy. Despite discoveries in the past few years, of new miRNA targets, further studies are needed to untangle the network linking programmed cell death to miRNA regulation of death receptors. This will hopefully lead to new therapeutic treatments for different kind of cancers.

Acknowledgements. This work was partially supported by funds from Associazione Italiana Ricerca sul Cancro, AIRC (GC), MIUR-FIRB (RBIN04J4J7), EU grant EMIL (European Molecular Imaging Laboratories Network) contract No 503569. We thank Dr. Vittorio de Franciscis and Michael Latronico for the revision of this article.

1. Du T, Zamore PD. microPrimer: the biogenesis and function of microRNA. Development 2005; 132: 4645-4652.

2. Bartel DP. MicroRNAs: genomics, biogenesis, mechanism, and function. Cell 2004; 116 : 281-297.

3. Alvarez-Garcia I, Miska EA. MicroRNA functions in animal development and human disease. Development 2005; 132: 4653-4662.

4. Lovis P, Gattesco S, Regazzi R. Regulation of the expression of components of the exocytotic machinery of insulin-secreting cells by microRNAs. Biol Chem 2008; $\mathbf{3 8 9}$ 305-312.

5. Yanaihara N, Caplen N, Bowman E, Seike M, Kumamoto K, Yi M et al. Unique microRNA molecular profiles in lung cancer diagnosis and prognosis. Cancer Cell 2006; 9: 189-198.

6. Rajewsky N, Socci ND. Computational identification of microRNA targets. Dev Biol 2004; 267: 529-535.

7. Bodmer JL, Schneider P, Tschopp J. The molecular architecture of the TNF superfamily. Trends Biochem Sci 2002; 27: 19-26.

8. Wiley SR, Schooley K, Smolak PJ, Din WS, Huang CP, Nicholl JK et al. Identification and characterization of a new member of the TNF family that induces apoptosis. Immunity 1995; 3: 673-682.

9. Ashkenazi A. Targeting death and decoy receptors of the tumour-necrosis factor superfamily. Nat Rev Cancer 2002; 2: 420-430.

10. Kischkel FC, Lawrence DA, Chuntharapai A, Schow P, Kim KJ, Ashkenazi A. Apo2 L/TRAIL-dependent recruitment of endogenous FADD and caspase- 8 to death receptors 4 and 5. Immunity 2000; 12: 611-620.

11. Sheridan JP, Marsters SA, Pitti RM, Gurney A, Skubatch M, Baldwin D et al. Control of TRAIL-induced apoptosis by a family of signaling and decoy receptors. Science 1997; 277: 818-821.

12. Griffith TS, Stokes B, Kucaba TA, Earel Jr JK, VanOosten RL, Brincks EL et al. TRAIL gene therapy: from preclinical development to clinical application. Curr Gene Ther 2009; 9: 9-19.

13. Ovcharenko D, Kelnar K, Johnson C, Leng N, Brown D. Genome-scale microRNA and small interfering RNA screens identify small RNA modulators of TRAIL-induced apoptosis pathway. Cancer Res 2007; 67: 10782-10788.

14. Chan JA, Krichevsky AM, Kosik KS. MicroRNA-21 is an antiapoptotic factor in human glioblastoma cells. Cancer Res 2005; 65: 6029-6023.

15. Corsten MF, Miranda R, Kasmieh R, Krichevsky AM, Weissleder R, Shah K. MicroRNA-21 knockdown disrupts glioma growth in vivo and displays synergistic cytotoxicity with neural precursor cell delivered S-TRAIL in human gliomas. Cancer Res 2007; 67: 8994-9000.

16. Mott JL, Kobayashi S, Bronk SF, Gores GJ. mir-29 regulates Mcl-1 protein expression and apoptosis. Oncogene 2007; 26: 6133-6140.

17. Chen L, Willis SN, Wei A, Smith BJ, Fletcher Jl, Hinds MG et al. Differential targeting of prosurvival Bcl-2 proteins by their BH3-only ligands allows complementary apoptotic function. Mol Cell 2005; 17: 393-403.
18. Cuconati $A$, Mukherjee $\mathrm{C}$, Perez $\mathrm{D}$, White $\mathrm{E}$. DNA damage response and $\mathrm{MCL}-1$ destruction initiate apoptosis in adenovirus-infected cells. Genes Dev 2003; 17: 2922-2932.

19. Garofalo M, Quintavalle C, Di Leva G, Zanca C, Romano G, Taccioli C et al. MicroRNA signatures of TRAIL resistance in human non-small cell lung cancer. Oncogene 2008; 27: 3845-3855.

20. Felli N, Fontana L, Pelosi E, Botta R, Bonci D, Facchiano F et al. MicroRNAs 221 and 222 inhibit normal erythropoiesis and erythroleukemic cell growth via kit receptor downmodulation. Proc Natl Acad Sci USA 2005; 102: 18081-18086.

21. le Sage C, Nagel R, Egan DA, Schrier M, Mesman E, Mangiola A et al. Regulation of the p27(Kip1) tumor suppressor by miR-221 and miR-222 promotes cancer cell proliferation. EMBO J 2007; 26: 3699-3708.

22. Wang P, Qiu W, Dudgeon C, Liu H, Huang $C$ et al. PUMA is directly activated by NF-kappaB and contributes to TNF-alpha-induced apoptosis. Cell Death Differ advance online publication, 15 May 2009; doi:10.1038/cdd.2009.51.

23. Zapata JM, Llobet D, Krajewska M, Lefebvre S, Kress CL, Reed JC. Lymphocyte-specific TRAF3 transgenic mice have enhanced humoral responses and develop plasmacytosis, autoimmunity, inflammation, and cancer. Blood 2009; 113: 4595-4603.

24. Tracey D, Klareskog L, Sasso EH, Salfeld JG, Tak PP. Tumor necrosis factor antagonist mechanisms of action: a comprehensive review. Pharmacol Ther 2008; 117: 244-279.

25. Taganov KD, Boldin MP, Chang KJ, Baltimore D. NF-kappaB-dependent induction of microRNA miR-146, an inhibitor targeted to signaling proteins of innate immune responses. Proc Natl Acad Sci USA 2006; 103: 12481-12486.

26. Tili E, Michaille JJ, Cimino A, Costinean S, Dumitru CD, Adair B et al. Modulation of miR-155 and miR-125b levels following lipopolysaccharide/TNF-alpha stimulation and their possible roles in regulating the response to endotoxin shock. $J$ Immunol 2007; 179: 5082-5089.

27. O'Connell RM, Taganov KD, Boldin MP, Cheng G, Baltimore D. MicroRNA-155 is induced during the macrophage inflammatory response. Proc Natl Acad Sci USA 2007; 104: 1604-1609.

28. Bazzoni F, Rossato M, Fabbri M, Gaudiosi D, Mirolo M, Mori $L$ et al. Induction and regulatory function of miR-9 in human monocytes and neutrophils exposed to proinflammatory signals. Proc Natl Acad Sci USA 2009; 106: 5282-5287.

29. Stennicke HR, Jürgensmeier JM, Shin H, Deveraux Q, Wolf BB, Yang X et al. Pro-caspase-3 is a major physiologic target of caspase-8. J Biol Chem 1998; 273: 27084-27090.

30. Scaffidi C, Fulda S, Srinivasan A, Friesen C, Li F, Tomaselli KJ et al. Two CD95 (APO-1/ Fas) signaling pathways. EMBO J 1998; 17: 1675-1687.

31. Shell S, Park SM, Radjabi AR, Schickel R, Kistner EO, Jewell DA et al. Let-7 expression defines two differentiation stages of cancer. Proc Natl Acad Sci USA 2007; 104: 11400-11405.

32. Papagiannakopoulos T, Shapiro A, Kosik KS. MicroRNA-21 targets a network of key tumor-suppressive pathways in glioblastoma cells. Cancer Res 2008; 68: 8164-8172.

33. Chen Y, Liu W, Chao T, Zhang Y, Yan X, Gong Y et al. MicroRNA-21 down-regulates the expression of tumor suppressor PDCD4 in human glioblastoma cell T98G. Cancer Lett 2008; 272: 197-205.

34. Gressner O, Schilling T, Lorenz K, Schulze Schleithoff E, Koch A, Schulze-Bergkamen H et al. TAp63alpha induces apoptosis by activating signaling via death receptors and mitochondria. EMBO J 2005; 24: 2458-2471.

35. Zhang Z, Li Z, Gao C, Chen P, Chen J, Liu W et al. miR-21 plays a pivotal role in gastric cancer pathogenesis and progression. Lab Invest 2008; 88: 1358-1366.

36. Fornari F, Gramantieri L, Ferracin M, Veronese A, Sabbioni S, Calin GA et al. MiR-221 controls CDKN1C/p57 and CDKN1B/p27 expression in human hepatocellular carcinoma. Oncogene 2008; 27: 5651-5661.

37. Meng F, Henson R, Wehbe-Janek H, Ghoshal K, Jacob ST, Patel T. MicroRNA-21 regulates expression of the PTEN tumor suppressor gene in human hepatocellular cancer. Gastroenterology 2007; 133: 647-658.

38. Zhao JJ, Lin J, Yang H, Kong W, He L, Ma X et al. MicroRNA-221/222 negatively regulates estrogen receptor alpha and is associated with tamoxifen resistance in breast cancer. J Biol Chem 2008; 283: 31079-31086.

39. Petrocca F, Visone R, Onelli MR, Shah MH, Nicoloso MS, de Martino I et al. E2F1regulated microRNAs impair TGFbeta-dependent cell-cycle arrest and apoptosis in gastric cancer. Cancer Cell 2008; 13: 272-286.

40. Inomata M, Tagawa H, Guo YM, Kameoka Y, Takahashi N, Sawada K. MicroRNA-17-92 down-regulates expression of distinct targets in different B-cell lymphoma subtypes. Blood 2009; 113: 396-402.

41. O'Donnell KA, Wentzel EA, Zeller KI, Dang CV, Mendell JT. c-Myc-regulated microRNAs modulate E2F1 expression. Nature 2005; 435: 839-843.

42. Gironella M, Seux M, Xie MJ, Cano C, Tomasini R, Gommeaux J et al. Tumor protein 53-induced nuclear protein 1 expression is repressed by miR-155, and its restoration inhibits pancreatic tumor development. Proc Natl Acad Sci USA 2007; 104: 16170-16175.

43. Cimmino A, Calin GA, Fabbri M, lorio MV, Ferracin M, Shimizu M et al. miR-15 and miR-16 induce apoptosis by targeting BCL2. Proc Natl Acad Sci USA 2005; 102: 13944-13949.

44. Johnson SM, Grosshans H, Shingara J, Byrom M, Jarvis R, Cheng A et al. RAS is regulated by the let-7 microRNA family. Cell 2005; 120: 635-647.

45. Sampson VB, Rong NH, Han J, Yang Q, Aris V, Soteropoulos P et al. MicroRNA let-7a down-regulates MYC and reverts MYC-induced growth in Burkitt lymphoma cells. Cancer Res 2007; 67: 9762-9770. 
46. He L, He X, Lim LP, de Stanchina E, Xuan Z, Liang Y et al. A microRNA component of the p53 tumour suppressor network. Nature 2007; 447: 1130-1134.

47. Yamakuchi M, Lowenstein CJ. MiR-34, SIRT1 and p53: the feedback loop. Cell Cycle 2009; 8: 712-715.

48. Bommer GT, Gerin I, Feng Y, Kaczorowski AJ, Kuick R, Love RE et al. p53-mediated activation of miRNA34 candidate tumor-suppressor genes. Curr Biol 2007; 17: 1298-1307.
49. Lin CJ, Gong HY, Tseng HC, Wang WL, Wu JL. miR-122 targets an anti-apoptotic gene, Bcl-w, in human hepatocellular carcinoma cell lines. Biochem Biophys Res Commun 2008 375: 315-320.

50. Su H, Yang JR, Xu T, Huang J, Xu L, Yuan Y et al. MicroRNA-101, down-regulated in hepatocellular carcinoma, promotes apoptosis and suppresses tumorigenicity. Cancer Res 2009; 69: 1135-1142. 